мическая наука современной России - 2017. № 2(77). - С. 78-89.

6. Птицефабрика нанесла ущерб на 73 миллиона рублей. - Режим доступа: https://news.sarbc. $\mathrm{ru} /$ main/2017/11/03/207793.html.

7. Тихомиров Н.П., Потравный И.М., Тихомирова T.M. Методы анализа и управления эколого-экономическими рисками: учеб. пособие для вузов / под ред. Н.П. Тихомирова. - М.: ЮНИТИ-ДАНА, 2003. - 350 с.

8. United Nations Environment Programme, 2015. - URL: un.org>en/ecosoc/integration/2015/ pdf/unep.pdf.

Воротников Игорь Леонидович, $\partial-p$ экон. наук, проф., зав. кафедрой «Организация производства и управление бизнесом в АПК», Саратовский государс- твенный аграрный университет имени Н.И. Вавилова. Россия.

Колотырин Константин Павлович, $\partial-p$ экон. наук. проф. кафедры «Организация производства и управление бизнесом в АПК», Саратовский государственный аграрный университет имени Н.И. Вавилова. Россия.

410012, г. Сарстов, Театральная пл., 1.

Тел.:(8445)26-27-83.

Киреева Елена Андреевна, стариий преподаватель кафедры банковского дела, денег и кредита, Саратовский социально-экономический институт (филиал) «РЭУ им. Г.В. Плеханова». Россия.

410003, г. Саратов, ул. Радищева, 89.

Тел.:(8452) 36-28-23.

Ключевъе слова: инвестииин; риски; сельское хозяйство; накопленный экологический ущерб; стимулирование.

\title{
IMPROVEMENT OF THE SYSTEM OF INVESTMENT PROJECTS MANAGEMENT OF LIQUIDATION OF ACCUMULATED ENVIRONMENTAL DAMAGE IN THE AIC
}

Vorotnikov Igor Leonidovich, Doctor of Economic Sciences, Professor, Head of the chair "Organization of Production and Business Management in the Agroindustrial Complex" Saratov State Agrarian University named after N.I. Vavilov. Russia.

Kolotyrin Konstantin Pavlovich, Doctor of Economic Sciences, Professor of the chair "Organization of Production and Business Management in the Agroindustrial Complex" Saratov State Agrarian University named after N.I. Vavilov. Russia.

Kireeva Elena Andreevna, Senior Teacher of the chair "Banking, Money and Credit", Saratov Socio-Economic Institute, Russian Economic University named after G.V. Plekhanov. Russia.
Keywords: investments; risks; agriculture; accumulated environmental damage; stimulation.

The main problems associated with the implementation of investment activities in the framework of the elimination of accumulated environmental damage in the agro-industrial complex are considered. Among the main environmental problems in agriculture, land pollution is the by-products of agricultural activities. The necessity of attracting financial resources within the framework of targeted investment is justified. In order to stimulate investors in the implementation of projects of accumulated environmental damage in agriculture, a phased implementation of instruments to reduce investor risks based on modern administrative and economic approaches is proposed.

\section{СОВЕРШЕНСТВОВАНИЕ ЗЕМЕЛЬНЫХ ОТНОШЕНИЙ КАК ОСНОВА РАЗВИТИЯ СЕЛЬСКИХ ТЕРРИТОРИЙ РЕГИОНА}

\author{
КАЧАНОВ Александр Иванович, Саратовская областная организация профсоюза \\ работников агропромышленного комплекса
}

ФИРСОВ Александр Иванович, Поволжский научно-исследовательский институт экономики и организации АПК

Основная часть земель сельскохозяйственного назначения в виде земельных долей стала собственностью граждан и юридических лии, их четвертая часть находится в государственной и мунищипальной собственности. Из земель, используемых сельхозорганизациями Саратовской области, 24 \% находятся в собственности, 72 \% - в аренде и 4 \% - в стадии оформления. Между арендодателями и арендаторами часто возникают разногласия, которые законодательно не регулируются. Для успешного функиионирования института аренды необходимо законодательное решение комплекса проблем арендного землепользования, в том числе разработка положений об оценке земли, формах и нормах арендной платы.

Введение. Современные тенденции развития и сложившееся социально-экономическое состояние АПК препятствуют самообеспеченности продовольствием и определяют низкую рентабельность сельхозпредприятий, недостаточный уровень 
развития инновационной деятельности, социальной сферы и инфраструктуры, формируя новые социальные и экономические отношения на селе [5]. Главным фактором развития этих отношений выступают отношения собственности на землю. В период перехода к частной собственности на средства производства и рыночным отношениям одни ученые идеализировали приватизацию государственной земельной собственности в виде купли - продажи земельных угодий. Другие видели будущее аграрной сферы в укреплении государственной собственности на землю на основе развития арендных отношений.

В настоящее время введение института земельной собственности в форме условных земельных долей ряд ученых считает ошибочным [11]. Низкая результативность земельной реформы, по мнению исследователей, заключается в односторонней ориентации на либерализацию земельных отношений и саморегулирующую роль рыночного механизма, упрощенного понимания земельных отношений как элементарной системы, основанной на частной собственности и свободной купле-продаже земли, исключающей какое-либо государственное регулирование [7]. Целью данной статьи является изучение земельных отношений, и прежде всего арендных, на сельских территориях региона и предложение законодательных инициатив с целью урегулирования разногласий между арендодателями и арендаторами, что в свою очередь должно стать одним из путей развития современного села.

Методика исследований. Научные исследования проводились сектором развития сельских территорий на базе трудов ведущих отечественных и зарубежных ученых в области устойчивого развития сельских территорий, агропромышленного комплекса и местного самоуправления, методических и справочных материалов, данных Федеральной службы государственной статистики и территориальной службы статистики $\mathrm{Ca}$ ратовской области, статистической и оперативной информации органов местного самоуправления муниципальных районов, нормативных правовых актах государственных, региональных и местных органов власти, результатах исследований, проведенных ранее ПНИИ ЭО АПК и других научных учреждений. Использованы методы моно- графического; экономико-статистического; расчетно-конструктивного исследования и социологического опроса.

Результатьи исследований. Установлено, что в результате перехода к новым формам землевладения в собственность граждан перешло 63,4 \% земель сельскохозяйственного назначения, на долю юридических лиц приходится 10,7 \%. В государственной и муниципальной собственности сосредоточено 25,9 \% земель, из которых 20,0 \% приходится на неразграниченную собственность, а на собственность РФ и субъекта РФ и муниципальную приходится 3,6 \% и 2,3 \% соответственно (табл. 1).

Анализ землевладения показал, что подавляющая их часть имеет конкретного собственника, но более 28 тыс. земельных долей с площадью более полумиллиона гектаров признаны невостребованными (табл. 2). Средние размеры земельных долей по Саратовской области составляют от 8 га пашни на черноземных почвах до 20-25 га в засушливой степи и совпадают с величиной дореволюционного земельного надела на крестьянский двор.

Спустя столетие оказалось, что на таких клочках вести товарное хозяйство весьма проблематично. Большая часть собственников земельных долей не в состоянии самостоятельно обрабатывать свой земельный надел и вынуждена сдавать его в аренду. Арендные отношения строятся на основе договора, в котором определены сроки, арендная плата, форма расчета, механизм решения возникающих споров. К основным методам определения арендной платы относятся следующие: рыночных арендных ставок, затрат собственника земли, долевого участия в чистом доходе, определения арендной платы в зависимости от уровня урожайности, имущественного пая и трудового участия собственника земли, а также нормативно-рентный метод $[1,6,13]$.

Однако механизмы регулирования арендных отношений и методы определения арендной платы требуют дальнейшего совершенствования. Формы и величина оплаты аренды земельных долей многообразны, но в большинстве сводятся к натуральной оплате - зерном, соломой и другой продукцией и услугами для ведения личного подсобного хозяйства. Так, в ООО «Агрофирма Рубеж» Пугачевского района в собственности 24443 га, в аренде 58733 га. У предприятия три вида арендода- 
Структура распределения земель сельскохозяйственного назначения Саратовской области по формам собственности по состоянию на 01.01 .2017 г. [9]

\begin{tabular}{|c|c|c|}
\hline Земли сельскохозяйственного назначения & Площадь, га & $\%$ \\
\hline Всего & 8587503 & 100,0 \\
\hline В том числе: в собственности граждан & 5441626 & 63,4 \\
\hline в собственности юридических лиц & 922452 & 10,7 \\
\hline в государственной и муниципальной собственности & 2223425 & 25,9 \\
\hline из нее: в собственности РФ & 312152 & 3,6 \\
\hline в собственности субъекта РФ & 312152 & 3,6 \\
\hline в муниципальной собственности & 194053 & 2,3 \\
\hline Неразграниченная собственность & 1713701 & 20,0 \\
\hline
\end{tabular}

Таблица 2

Количество и общая площадь земельных долей (ед. и тыс. га) земель сельскохозяйственного назначения, признанных невостребованными в 2015 г. по состоянию на 01.01.2016 г. [9]

\begin{tabular}{|c|c|c|}
\hline Структура владения земельными долями и участками & $\begin{array}{l}\text { Количество, } \\
\text { ед. }\end{array}$ & $\begin{array}{c}\text { Площадь, } \\
\text { тыс. га }\end{array}$ \\
\hline $\begin{array}{l}\text { Земельные доли в праве общей собственности на земельные участки из } \\
\text { земель сельскохозяйственного назначения }\end{array}$ & 222854 & 4033,3 \\
\hline $\begin{array}{l}\text { Земельные доли, включенные в списки невостребованных земельных } \\
\text { долей }\end{array}$ & 21505 & 376,0 \\
\hline $\begin{array}{l}\text { Земельные доли, признанные по решению суда муниципальной собствен- } \\
\text { ностью }\end{array}$ & 5556 & 327,3 \\
\hline $\begin{array}{l}\text { Земельные участки, образованные в счет невостребованных земельных } \\
\text { долей, признанных муниципальной собственностью }\end{array}$ & 1172 & 40,8 \\
\hline $\begin{array}{l}\text { Земельные участки, образованные в счет невостребованных земельных } \\
\text { долей, признанных по решению суда собственностью субъекта Российс- } \\
\text { кой Федерации (реализация полномочий, действовавших до 01.07.2011 г.) }\end{array}$ & 0 & 0 \\
\hline
\end{tabular}

телей земельных ресурсов - физические лица, муниципалитет и юридические лица. Большая часть земельных ресурсов в хозяйстве на правах аренды. В хозяйстве ведется реестр земельных дольщиков, договора аренды заключены на длительный срок. Оплата за земельную долю составляет 5 тыс. руб. Хотя в договорах и не зафиксирована, но широко практикуется оплата земельной доли зерном. Независимо от кадастровой стоимости земли постоянная сумма в 5 тыс. руб. - одинаковая для всех долей. В ИП (физ. лицо) Шиндин Василий Петрович того же района арендуются земли, в основном ранее не обрабатываемые и введенные в оборот предпринимателем. Всего обрабатывается около 15 тыс. га, из которых треть земель находится в собственности, остальные арендуются. В 2014 г. на земельную долю владельцам приходилось 1,5 т зерна, при этом солому в тюках бесплатно развозили по домам. Оказывалась и помощь в содержании скота. В 2017 г. стоимость аренды выросла до 10 тыс. руб., оплата или зерном или соломой. В ряде сельхозорганизаций и фермерских хозяйств оплата за земельную долю (9,5 га пашни) составляет 500 кг зерна, 5 л подсолнечного масла и 2 т соломы. Хотя все жители села получили земельные доли из земель сельскохозяйственного назначения (в стране насчитывается 11,6 млн собственников), это не привело к существенному увеличению бюджета сельской семьи. Как показали исследования ученых института аграрных проблем РАН (г. Саратов), только 9\% респондентов включили выплаты за земельные доли в перечень источников дохода [3]. Как показали результаты проведенных авторамианкетных опросов селян Саратовской области, наличие земельной и имущественной доли не увеличили семейный бюджет. В 2005 г. респонденты имели следующие источники доходов: заработная плата на предприятии, в учреждениях - 83,6 \% опрошенных; доход от ЛПХ - 41,8 \%; доходы от коммерческой деятельности - 2,7 \%; пенсии, пособия, дотации и некоторые другие доходы - 29,1 \%. Дивиденды и ценные бумаги как источник доходов указали 0,9 \% опрошенных. По данным опроса 2013 г. заработная плата на предприятии, в учреждениях указана у 96 \% опрошенных и в общей сумме доходов составляла от 15 до $100 \%$; доход от ЛПХ указан у $80 \%$. что составило от 10 до $70 \%$ от общей суммы доходов. 
Пенсии, пособия, дотации и некоторые другие доходы указаны у 32 \% опрошенных. Доход от дивидендов и ценных бумаг не указан. Вместе с тем основными формами конфликтных ситуаций в 2005 и 2013 гг. были земельные и имущественные споры (их указали 43,2 и 54 \% опрошенных), а также бытовые конфликты (21,6 и $22 \%$ опрошенных).

Надежды, возлагаемые на получение дохода от сдачи в аренду земли, оказались иллюзорными. И хотя за последние годы уровень жизни сельских жителей повысился, он остается довольно скромным. При оценке расходов семей жителей Саратовского села, как показали результаты анкетного опроса в 2005 и 2013 гг., доля опрошенных, которым средств хватает на пропитание и покупку самых необходимых вещей, выросла с 67 \% в 2005 г. до 72 \% в 2013 г., на покупку предметов длительного пользования - с 5,5 до $16 \%$. Число респондентов, которым средств не хватает на самое главное, даже на питание, уменьшилось с 29,1 до 6 \%. Таким образом, жители современного села, по сравнению с 2005 г. представляются только несколько более обеспеченными, поэтому и весьма скромные доходы от сдачи в аренду земли не были бы лишними [10].
Анализ движения земельных долей показал, что основная часть обрабатываемой пашни находится в аренде, при этом земли продолжаются скупаться в собственность. Площадь земель, находящихся в собственности сельхозорганизаций, увеличилась за 2011-2015 гг. с 640502 га до 708364 га, в аренде - с 1691636 до 2127324 га. Площадь оформляемых земель уменьшились с 336642 до 114721 га (табл. 3).

В Пугачевском районе Саратовской области все земли оформлены. В собственности сельхозорганизациях находится 16 \% земель, в аренде - 84 \%. Максимальные площади земель в собственности имеют сельскохозяйственные предприятия с организационно-правовой формой хозяйствования - общества с ограниченной ответственностью (ООО). ООО «Агрофирма Рубеж» из 82200 га сельхозугодий владеет 24467 га, арендует 58773 га. В сельхозорганизации ООО «Золотой Колос Поволжья» из 22884 га земли 2932 га являются собственностью и 19952 га арендуется, в ООО «Преображенская» 1081 га - собственностью и 7859 га арендуется. В сельхозкооперативах практически все земельные площади арендованы у владельцев земельных долей (табл. 4).

Таблица 3

Динамика структуры использования земли сельхозорганизациями Саратовской области, га [8]

\begin{tabular}{|c|c|c|c|c|}
\hline \multirow{2}{*}{ Год } & \multirow{2}{*}{$\begin{array}{c}\text { Всего } \\
\text { земли }\end{array}$} & в собственности & в аренде & $\begin{array}{c}\text { в процессе } \\
\text { оформления }\end{array}$ \\
\cline { 2 - 5 } & 2668780 & 640502 & 1691636 & 336642 \\
\hline 2011 & 2433297 & 362761 & 1852275 & 218261 \\
\hline 2012 & 2750845 & 540983 & 2010596 & 199266 \\
\hline 2013 & 2866510 & 599025 & 2093083 & 174402 \\
\hline 2014 & 2950409 & 708364 & 2127324 & 114721 \\
\hline 2015 & \multicolumn{3}{|c}{} \\
\hline
\end{tabular}

Таблица 4

Использование земли сельхозорганизациями Пугачевского района Саратовской области в 2015 г., га [8]

\begin{tabular}{|l|c|c|c|c|}
\hline \multirow{2}{*}{ Сельхозпредприятия и район в целом } & \multirow{2}{*}{ Всего } & \multicolumn{2}{|c|}{ В том числе } & \multirow{2}{*}{$\begin{array}{c}\text { земли } \\
\end{array}$} \\
& земли, га & в собственности & в аренде & в аренде \\
\hline Район в целом & 199380 & 31618 & 167762 & 84 \\
\hline ООО «Агрофирма Рубеж» & 83200 & 24467 & 58733 & 71 \\
\hline ООО «Агропродукт» & 10125 & 452 & 9673 & 96 \\
\hline ООО «Вектор» & 6166 & 51 & 6115 & 99 \\
\hline ООО «Золотой Колос Поволжья» & 22884 & 2932 & 19952 & 87 \\
\hline ООО «Любицкое» & 15771 & 1140 & 14631 & 93 \\
\hline ООО «Освобождение» & 2215 & 160 & 2055 & 93 \\
\hline ООО «Агрофирма Простор» & 3876 & 298 & 3578 & 92 \\
\hline ООО «Преображенское» & 8940 & 1081 & 7859 & 85 \\
\hline СА «Камеликская» & 3270 & 115 & 3155 & 96 \\
\hline СХА «Калинино» & 15175 & 488 & 14687 & 97 \\
\hline СХА «Колос» & 774 & - & 774 & 100 \\
\hline СХА «Урожай» & 11203 & - & 11203 & 100 \\
\hline ФГУП «Солянское» Россельхозакадемии & 12351 & - & 12351 & 100 \\
\hline
\end{tabular}

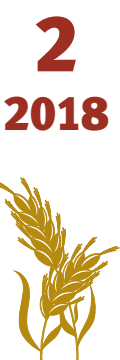


Процесс скупки земель за последние годы замедляется в связи со сложным финансовым состоянием отрасли. Среди сельскохозяйственных предприятий реальную возможность покупки земель имеют крупные предприятия. В настоящее время основным источником дохода сельхозпредприятий области является растениеводство. При средней выручке от реализации продукции на сумму чуть более 19 млрд руб., по 39,3 \% приходится на зернобобовые и подсолнечник, на сою - $1,3 \%$; на овощи открытого грунта - около $1,5 \%$ и 8 \% на овощи закрытого грунта; на сахарную свеклу - 2 \%. На прочую продукцию растениеводства и реализацию продукции растениеводства собственной продукции растениеводства приходится около 8 \% выручки. Выручка от возделывания рыжика, льна, картофеля, садоводства и бахчеводства составляет не более $1,9 \%$ от всей реализованной продукции. Так, средняя за последние три года прибыль в ООО «Золотой Колос Поволжья» составила 127,6 млн руб., ООО «Агрофирма «Рубеж» - 97 млн руб., в ООО «Преображенское» и ООО «Агрофирма Простор» - 18 и 20 млн руб., в ООО «Век- тор» и $\mathrm{OOO} \mathrm{«Агропродукт»} \mathrm{-} 2$ и 3 млн руб. В среднем на одно ООО района, при средней численности работников 120 чел., приходилось 33 млн руб. прибыли, на 1 работника - 276 тыс. руб. По сельхозкооперативам в среднем на одно предприятие прибыль составила около 7 млн руб., на 1 работника - 84 тыс. руб. Следует отметить, что ФГУП «Солянское» Россельхозакадемии, специализирующееся на семеноводстве зерновых культур, довольно успешное предприятие. В современных условиях заработная плата не зависит от результатов хозяйственной деятельности предприятий $[2,4,12]$ и остается на достаточно низком уровне (табл. 5).

Заключение. Таким образом, в современном сельскохозяйственном землепользовании арендная плата за земельные доли выплачивается в основном в натуральном виде, не имеет достаточного научного обоснования и не увязана с продуктивности земель и доходностью производства. Упорядочение взимания арендной платы за земельные доли может стать одним из источников пополнения семейного дохода и снизить социальную напряженность на селе.

Таблица 5

\section{Средняя прибыль на 1 предприятие (до налогообложения), на 1 работающего и среднемесячная} заработная плата по предприятиям Пугачевского района в среднем за 2013-2015 гг. [8]

\begin{tabular}{|l|c|c|c|c|}
\hline \multicolumn{1}{|c|}{ Показатель } & $\begin{array}{c}\text { Средняя } \\
\text { прибыль } \\
\text { за год, } \\
\text { тыс. руб. }\end{array}$ & $\begin{array}{c}\text { Средняя чис- } \\
\text { ленность } \\
\text { работающи, } \\
\text { чел. }\end{array}$ & $\begin{array}{c}\text { Прибыль на } \\
\text { 1 работника, } \\
\text { тыс. руб. }\end{array}$ & $\begin{array}{c}\text { Средняя } \\
\text { начисленная } \\
\text { зарплата, руб. }\end{array}$ \\
\hline ООО «Агрофирма Рубеж» & 96963 & 612 & 158 & 14586 \\
\hline ООО «Агропродукт» & 2905 & 40 & 73 & 5137 \\
\hline ООО «Вектор» & 2364 & 23 & 101 & 6864 \\
\hline ООО «Золотой Колос Поволжья» & 127649 & 139 & 920 & 14489 \\
\hline ООО «Любицкое» & -2635 & 45 & -58 & 8291 \\
\hline ООО «Освобождение» & -889 & 12 & -76 & 5550 \\
\hline ООО Агрофирма «Простор» & 19814 & 17 & 1124 & 6013 \\
\hline ООО «Преображенское» & 17571 & 68 & 258 & 10057 \\
\hline В среднем на одно ООО & 32968 & 120 & 276 & 13101 \\
\hline СА «Камеликская» & 5579 & 42 & 134 & 9987 \\
\hline СХА «Калинино» & 14717 & 130 & 113 & 9437 \\
\hline СХА «Колос» & 1743 & 14 & 128 & 10628 \\
\hline СХА «Урожай» & 4849 & 135 & 36 & 10561 \\
\hline В среднем на одну СХА (СА) & 6722 & 80 & 84 & 9862 \\
\hline ФГУП «Солянское» & 19606 & 38 & 511 & 14184 \\
\hline Район & 309915 & 1314 & 236 & 12115 \\
\hline
\end{tabular}


Арендованные земельные доли физических лиц не должны служить залоговой базой для кредитных организаций, подвергаться аресту и другим действиям, приостанавливающим хозяйственную деятельность и не подвергаться процедуре банкротства, а земля должна использоваться по назначению. При сдаче в аренду земель муниципальных образований величина арендной платы также должна иметь научное обоснование.

\section{СПИСОК ЛИТЕРАТУРЫ}

1. Ададимова Л.Ю. Экономическая оценка сельхозугодий в условиях аренды земельных долей // Настоящее и будущее агропромышленного комплекса России: сб. материалов V Bсероссийского конгресса экономистов-аграрников, посвященного 125-летию А.В. Чаянова (21-22 ноября 2013 г., Москва). - Т. 11 / ФБГНУ «Росинформагротех». - М., 2014.- С. 130-133.

2. Аукина И.Г., Голубева А.А., Раздобарова М.Н. Совершенствование оплаты труда работников лесхозов // Аграрный научный журнал. 2016. - № 11. - С. 63-69.

3. Великий П.П. Социальная политика на селе: новые вызовы, старые ограничения // Журнал исследований социальной политики. - Режим доступа: cyberleninka.ru>Грнти>...-na-sele-novyevyzov.

4. Голубева А.А. Особенности эволюционного развития агроэкономики // АПК: экономика, управление. - 2001. - № 6. - С. 74-77.

5. Голубева А.А., Мурашова А.С., Норовяткина E.M. Ориентиры развития сельского хозяйства в новых условиях // Аграрный научный журнал. - 2015. - № 10. - С. 76-80.

6. Заворотин Е.Ф. Развитие земельных отношений в аграрном секторе экономики. - Саратов, Саратовский источник, 2014. - 367 с.

7. Миндрин А.С. Направления развития земельных отношений в сельском хозяйстве России // Научное обозрение: теория и практика. 2015. - № 4. -C. 25-32.
8. Официальный сайт министерства сельского хозяйства Саратовской области. - Режим доступа: minagro.saratov.gov.ru.

9. Официальный сайт ФБГУ Управление «Росреестр» по Саратовской области. - Режим доступа: rosreestr.ru>site...upravlenie...saratovskoyoblasti/.

10. Саратовская область в 2005 и 2013 гг.: итоги опроса по анкетам «Социально-экономическое развитие в сельском районе» и «Социально-экономическое развитие сельских территорий» / А.А. Черняев [и др.]; ГНУ ПНИИЭО АПК Россельхозакадемия, Саратовская областная организация профсоюза работников агропромышленного комплекса. - Саратов: типография ИП Климов К.А., 2014. - С. 33.

11. Семенов С.Н., Пашков В.П. Основные направления и школы экономических исследований земельной собственности в России // Научное обозрение. - 2012. - № 6. - С. 569-576.

12. Юркова М.С., Фирсов А.И. Эффективные формы экономических отношений на сельских территориях Саратовской области // Аграрный научный журнал. - 2017. - № 10. - С. 96-100.

13. Zavorotin E., Gordopolova A., Tiurina N., Yurkova $M$. Land relations: features of transformation in modern Russia // Економічний часопис-XXI. 2017. - T. 163. - № 1-2. - C. 56-59.

Качанов Александр Иванович, канд. экон. наук, председатель, Саратовская областная организация профсоюза работников агропромышленного комплекса. Россия.

410600, г. Саратов, ул. Сакко и Ваниетти, 55.

Тел.: (8452) 26-23-62.

Фирсов Александр Иванович, $\partial-p$ c.- $x$. наук, ведущий сотрудник сектора развития сельских территорий, Поволжский научно-исследовательский институт экономики и организации АПК. Россия.

410010, г. Саратов, ул. Шехурдина, 12.

Тел.: (8452) 64-06-47.

Ключевые слова: арендные отношения; земельные доли; аренда земель; социальные отношения; сельские территории; регион.

\section{LAND RELATIONS ENHANCEMENT AS A BASIS OF RURAL TERRITORIES DEVELOPMENT IN THE REGION}

Kachanov Aleksandr Ivanovich, Candidate of Economic Sciences, Chairman, Agro-Industrial Workers Union in the Saratov oblast. Russia.

Firsov Aleksandr Ivanovich, Doctor of Agricultural Sciences, Leading Researcher of rural territories development sector, Volga Research Institute of Economics and Organization of Agro-Industrial Complex. Russia.

Keywords: leases; land shares; land; social relations; rural areas.
The main part of lands for agricultural purpose by way of land shares has become citizens and legal entities properties, a quarter is state and municipal properties. The lands used by agricultural organizations of the Saratov oblast $24 \%$ are in a property, $72 \%$ - in a lease and $4 \%$ are on a stage of formalization. However disagreements between the lessor and the lessee about the subject oflease are not legally settled. Legislative resolution for complex of land rental problems and development of regulations of land evaluation and rental payment is necessary for successful functioning of lease institution. 